\title{
Perspectives on narrative medicine
}

This article was published in the following Dove Press journal: International Journal of COPD

\section{Amir-Seena Saberi-Movahed Syed Waqar}

Ahmad Salha

Faculty of Medicine, St George's Hospital Medical School, London, UK
Correspondence: Amir-Seena SaberiMovahed

Faculty of Medicine, St George's Hospital Medical School, Cranmer Terrace,

London SWI 7 ORE, UK

Tel +447592187575

Email seena.saberi@outlook.com

\section{Dear editor}

We read the article on the relationship between narrative medicine and the positive outcomes reflected in COPD management, by Banfi et $\mathrm{al}^{1}$ with great interest. We were particularly intrigued by how the simple documentation of parallel charts could improve the patient-doctor relationship and patient adherence to treatment. It made us evaluate narrative medicine from different perspectives.

The article ${ }^{1}$ highlights that narrative medicine improves the patient-doctor relationship and hence patient outcomes. Graffigna et $\mathrm{al}^{2}$ suggested a multidimensional association between the patient-doctor relationship, patient engagement, and medical adherence for patients with chronic conditions. All of which are critical elements in determining outcomes of COPD patients.

Banfi et $\mathrm{al}^{1}$ briefly explored ways narrative medicine can benefit doctors, allowing them to reflect upon their emotions, in addition to those of their patients. We were interested to find further evidence of this outside the realm of COPD. Nowaczyk ${ }^{3}$ explained that, when used by clinical geneticists, reflective narrative writing allowed patient encounters to be explored far beyond medical diagnosis, a much greater story that often allows physicians to relieve emotional unrest they face during practice. Moreover, Meier et $\mathrm{al}^{4}$ state possible consequences when physicians' emotions remain unassessed, including, compromised patient care, physician disengagement, depression, and burnout. Hence, this further evidences the benefits of narrative practice, given it can safeguard physicians from such complications amongst others.

To us as medical students, the importance of empathy is never understated. However, we are all witness to doctors who are at best indifferent, to the emotional state of patients, which can impede good patient care. Interestingly, Banfi et $\mathrm{al}^{1}$ found the terms within parallel charts to be most commonly disease-specific and that younger physicians struggled more to relate to their patients; what was not explored was the development of language of individual physicians within their parallel charts. It would be intriguing to see if evidence of emotion and empathy increased within later parallel charts of individual doctors over time. However, within the original article the number of parallel charts completed by each physician was quite limited, thus, a further study where each doctor completes several parallel charts, would be needed to assess this thought.

Although parallel charts strengthened the patient-doctor relationship, ${ }^{1}$ their use with all patients is not feasible given the time constraints imposed upon the profession by increasing patient numbers. Esch et $\mathrm{al}^{5}$ explored another approach to break down barriers between patients and doctors. One in which patients are given and actively encouraged to read their medical notes, consequently, patients commonly stated an 
improvement in the relationship with their doctor. A less time-consuming method for physicians, while still compelling them to be more thoughtful when writing notes.

Many chronic conditions, including COPD, exist whereby a patient's own choices directly impacts their health outcomes. Therefore, a relationship of trust between doctors and patients is paramount. The emotional aspects of chronic conditions make this difficult, however narrative medicine and similar techniques may positively influence both sides of this relationship.

\section{Disclosure}

The authors report no conflicts of interest in this communication.

\section{References}

1. Banfi P, Cappuccio A, Latella M, Reale L, Muscianisi E, Marini M. Narrative medicine to improve the management and quality of life of patients with COPD: the first experience applying parallel chart in Italy. Int J Chron Obstruct Pulmon Dis. 2018;13:287-297.

2. Graffigna G, Barello S, Bonanomi A. The role of Patient Health Engagement Model (PHE-model) in affecting patient activation and medication adherence: A structural equation model. PLoS One. 2017;12(6): e0179865.

3. Nowaczyk MJ. Narrative medicine in clinical genetics practice. Am J Med Genet A. 2012;158A(8):1941-1947.

4. Meier DE, Back AL, Morrison RS. The inner life of physicians and care of the seriously ill. JAMA. 2001;286(23):3007-3014.

5. Esch T, Mejilla R, Anselmo M, Podtschaske B, Delbanco T, Walker J. Engaging patients through open notes: an evaluation using mixed methods. BMJ Open. 2016;6(1):e010034. 


\section{Authors' reply \\ Antonietta Cappuccio \\ Maria Giulia Marini \\ Healthcare Area, Fondazione ISTUD, Milan, Italy}

Correspondence: Antonietta Cappuccio

Healthcare Area, Fondazione ISTUD, Piazza IV Novembre 7, Milan, Italy

Tel +393476457072

Email acappuccio@istud.it

\section{Dear editor}

We read the letter of Saberi-Movahed et al and we are pleased that our paper ${ }^{1}$ has aroused interest in other care professionals. Although the first articles on narrative medicine and the use of parallel charts were already published in the early $2000 \mathrm{~s},{ }^{2}$ there are few papers published on this topic and we, as a research center, are striving to give narrative research the acknowledgment and role it is worthy of.

In response to the doubts and curiosities expressed by Saberi-Movahed et al, we have already published other studies on the use of the parallel charts ${ }^{3,4}$ in patients suffering from fibromyalgia and from asthma and we encourage Master in Applied Narrative Medicine students to implement this practice in clinical the context, including oncology, palliative care, intensive care unit, and family practice.

In the current study, ${ }^{1}$ we analyzed the narrative language used by physicians within their parallel charts. In the beginning this was more "disease oriented", resembling the description of medical history, but then evolved in the final part and became more illness oriented and attentive to the whole person rather than the patient. As observed by SaberiMovahed et al though, the number of parallel charts written by each physician did not allow us to make any further analysis on the increase of empathy. The pulmonologists who participated in the project stated that they found benefit in writing the parallel charts and they wish to continue to use this tool, so we hope that we will be able to perform a new evaluation within a few years.
As stated by Saberi-Movahed et al, it took physicians a considerable amount of time, with an average mean of approximately 30 minutes, to write the parallel charts, but in this case the open script was quite structured for research purposes and it recalled all visits from the first encounter since today. Physicians participating in our training usually write their parallel charts in 10 minutes, therefore the writing time can be reduced if notes are taken at each visit.

With regard to the possibility of sharing parallel charts with patients, the parallel chart represents a cathartic instrument in which the doctor can understand and express his/her emotions and thoughts about the patient and, precisely for this reason, the decision to share or not share remains the clinician's. In fact, although recommended, not all narratives are suitable for sharing with patients who may not be ready to accept the complexity of their situation.

Parallel chart use is also a topic of teaching for future doctors and nurses while they are doing their internships in clinics, and is currently occurring in many academies. ${ }^{5}$

\section{Disclosure}

The authors report no conflicts of interest in this communication.

\section{References}

1. Banfi P, Cappuccio A, Latella M, Reale L, Muscianisi E, Marini M. Narrative medicine to improve the management and quality of life of patients with COPD: the first experience applying parallel chart in Italy. Int J Chron Obstruct Pulmon Dis. 2018;13:287-297.

2. Charon $\mathrm{R}$. The patient-physician relationship. Narrative medicine: a model for empathy, reflection, profession, and trust. JAMA. 2001;286(15): 1897-1902.

3. Marini MG, De Nardo D, Chesi P, Reale L. Narrative medicine and fibromyalgia. In: Farkas C, editor. Reading the Psychosomatic in Medical and Popular Culture. London: Routledge; 2018.

4. Cappuccio A, Latella M, Pelaia G, Menzella F, Pellegrini G, Marini MG. Narrative medicine to evaluate the relationship between clinicians and patients living with severe asthma. Eur Respir J. 2017;50(suppl 61): PA2779.

5. Marini MG. Narrative Medicine, Bridging the Gap between Evidence Based Care and Medical Humanities. New York, NY: Springer International Publishing; 2016.

Dove Medical Press encourages responsible, free and frank academic debate. The content of the International Journal of Chronic Obstructive Pulmonary Disease 'letters to the editor' section does not necessarily represent the views of Dove Medical Press, its officers, agents, employees, related entities or the International Journal of Chronic Obstructive Pulmonary Disease editors. While all reasonable steps have been taken to confirm the content of each letter, Dove Medical Press accepts no liability in respect of the content of any letter, nor is it responsible for the content and accuracy of any letter to the editor.

International Journal of COPD

\section{Publish your work in this journal}

The International Journal of COPD is an international, peer-reviewed journal of therapeutics and pharmacology focusing on concise rapid reporting of clinical studies and reviews in COPD. Special focus is given to the pathophysiological processes underlying the disease, intervention programs, patient focused education, and self management protocols.

\section{Dovepress}

This journal is indexed on PubMed Central, MedLine and CAS. The manuscript management system is completely online and includes a very quick and fair peer-review system, which is all easy to use. Visit $\mathrm{http}: / / \mathrm{www}$.dovepress.com/testimonials.php to read real quotes from published authors. 